\title{
SERUM CYSTATIN C IN PATIENTS WITH DELAYED GRAFT FUNCTION
}

\author{
M. Boncheva1, T. Gruev² and G. Nikolov ${ }^{1}$ \\ ${ }^{1}$ Medical University of Varna, Bulgaria \\ ${ }^{2}$ Department of Nephrology, Institute of Clinical Biochemistry, University Clinical Center, \\ Skopje, Macedonia
}

\begin{abstract}
Summary. Despite recent studies showing that serum Cystatin $\mathrm{C}$ (CysC) is a better marker for glomerular filtration rate (GFR) than the ubiquitously used creatinine, the clinical utility of these findings remains to be evaluated. This marker is very sensitive for allograft function after renal transplantation. The concentration of CysC was compared with that of the creatinine. Decreased renal function was followed in 64 transplanted patients. Serum CysC significantly correlated with creatinine in healthy controls $(r=0.625, p<0.0001)$, whereas in the transplanted patients the mean serum creatinine and CysC concentrations were: $81 \pm 13 \mathrm{mmol} / \mathrm{L}$ and $0.90 \pm$ $0.22 \mathrm{mg} / \mathrm{L}$, respectively. Serum CysC and creatinine significantly correlated throughout the post transplantation period ( $r=0.686, p<0.001)$, but we confirmed differences between kinetics of these parameters. In the first four days after transplantation the CysC concentration was normalized faster than the creatinine concentration. Development of acute rejection episode (between 5 and 7 days) showed high sensitivity and specificity of the changes of CysC compared with those of creatinine.
\end{abstract}

Key words: renal transplantation, delayed graft function, Cystatin C

\section{INTRODUCTION}

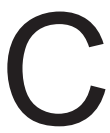

ystatin $\mathrm{C}(\mathrm{Cys} C)$ is a nonglycosylated basic protein $(13.36 \mathrm{kDa})$ and can be found in a variety of biologic fluids [1]. Cys $\mathrm{C}$ serum concentration is not influenced by gender, inflammation, or lean tissue mass and is regarded to be mainly determined by glomerular filtration rate (GFR) [2, 3]. CysC has been described as meeting many of the characteristics of an ideal GFR marker (e.g., endogenously produced at a constant rate, freely filtered in the glomerulus, 
neither reabsorbed nor secreted in the renal tubule, not extrarenally eliminated) and has been reported to be at least as accurate as the commonly used serum creatinine ( $\mathrm{SCr}$ ) to detect impaired renal function in various patient groups, including renal transplant patients [4-11].

In the recent literature, Cys $\mathrm{C}$ has been advocated as a new and more accurate estimate of GFR [1]. CysC is a $13 \mathrm{kDa}$ endogenous cysteine proteinase inhibitor produced by all nucleated cells at a constant rate and broken down completely in the renal tubuli [12]. CysC concentrations are independent of age and body weight, and there is no need for urine collection for clearance estimation. Furthermore, serum concentrations of CysC are not influenced by malignancy or inflammation. In contrast, the often-used SCr concentration is supposedly influenced by dietary intake, renal tubular metabolism, age, and variations in muscle mass. There are also various analytical difficulties with the widely used Jaffe colorimetric assay for creatinine. A slight decrease in GFR has been found in patients with hypothyroidism, which improved significantly after treatment [2, 3]. We wondered whether CysC would also be a good marker of renal function in case of thyroid dysfunction. Because thyroid hormones have general metabolic effects, the thyroid state could influence serum CysC concentrations.

Patients are at risk of acute damage to the transplanted kidney because of rejection or toxicity from immunosuppressant therapy. Earlier detection of renal damage may lead to more effective intervention. In a preliminary study, LeBricon et al. [13] first suggested that CysC was more sensitive than $\mathrm{SCr}$ for detecting decreases in GFR and delayed graft function in renal transplant patients. As in most studies, serum CysC measurements correlated well with $\mathrm{SCr}$ and creatinine clearance $(\mathrm{CrCl})$. However, in the three cases of acute renal rejection that were confirmed by biopsy, the increase in $\mathrm{Cys} C$ values was more pronounced than that observed for $\mathrm{SCr}$.

After renal transplantation, $\mathrm{SCr}$ is the most common marker for assessment of allograft function. In a steady-state muscular mass balance, the SCr concentration is assumed to reflect GFR [14]. However, SCr is far from being an ideal marker of GFR, despite its convenience and low cost [15]. SCr suffers a high degree of interindividual variability related to sex, age, body composition, and dietary factors [16]. With altered renal function, the $\mathrm{SCr}$ concentration increases only when the GFR is reduced by $>50 \%$. Furthermore, secretion or reabsorption of creatinine by the renal tubule is highly unpredictable, thus leading to under- or overestimation of GFR [15].

Numerous drugs and endogenous substances also interfere with the measurement of creatinine by the Jaffé technique or enzymatic methods, leading to falsely high or low creatinine values [17].

In this prospective study, CysC was evaluated as a marker of allograft function during the early postoperative transplantation period. Serum CysC was determined by a recently developed particle-enhanced immunoturbidimetric assay (DAKO). Serum CysC kinetics fwas compared with those of $\mathrm{SCr}$ used in our institution for estimation of GFR in transplant recipients. The results are discussed with the following 
clinical indicators of renal function: dialysis requirements, acute rejection, and treatment nephrotoxicity.

\section{MATERIAL AND METHODS}

Sixty-four patients with end-stage renal disease undergoing renal transplantation were included in this study. Primary diagnosis of the investigated patients was: chronic interstitial nephropathy $(n=8)$, diabetic glomerulopathy $(n=12)$, polycystic kidney disease $(n=3)$, nephrosclerosis $(n=3)$, focal segmental glomerulosclerosis $(n=10)$, IgA nephropathy $(n=8)$, membranous glomerulonephritis $(n=11)$, mesangiocapillary glomerulonephritis $(n=1)$, and unknown etiology $(n=4)$. Immunosuppressive regiment included steroids (methylprednisolone at the initial dose of 500 $\mathrm{mg}$, followed by $1 \mathrm{mg} / \mathrm{kg}^{-1} / \mathrm{day}^{-1}$, progressively tapered) and cyclosporine A (initial dose of $8 \mathrm{mg} / \mathrm{kg}^{-1} / \mathrm{day}^{-1}$, and then adjusted according to blood concentrations) or FK506 in cases of cyclosporine intolerance (at the dose of $0.1 \mathrm{mg} / \mathrm{kg}^{-1} / \mathrm{day}^{-1}$ ). The patients were classified into two groups according to the clinical diagnosis: with or without delayed graft function.

The control group consisted of 50 healthy persons. They were free of cardiac, liver or renal diseases or hypertension and had normal urine analysis and normal serum urea, creatinine and CysC concentrations.

\section{Methods}

Delayed graft function (DGF) was defined as a requirement for dialysis during the first 2 weeks after transplantation. All patients were on conventional dialysis. Episodes of acute rejection diagnosed by renal biopsy were treated with 5 days of intravenous methylprednisolone. This study was in accordance with the ethics standards of the Helsinki Declaration of 1975, as revised in 1983.

Allograft function was evaluated on a daily basis starting the day of surgery (day 0 ) and for 25 days thereafter or until hospital discharge, whichever occurred first. Blood (7 $\mathrm{mL}$ ) was drawn by venipuncture in a Vacutainer ${ }^{\circledR}$ Tube (Becton Dickinson) before centrifugation ( $3500 \mathrm{~g}$ at $20^{\circ} \mathrm{C}$ for $15 \mathrm{~min}$ ) and analyzed for creatinine and CysC. Creatinine concentration was enzymatically assayed on a INTEGRA biochemical analyzer. The sample volume was $10 \mu \mathrm{L}$, and the assay was performed at $37^{\circ} \mathrm{C}$; total analysis time was $7 \mathrm{~min}$. In our hands, the interassay imprecision ( $\mathrm{CV} ; \mathrm{n}=50)$ was $<3 \%$.

The concentration of CysC was measured using a DAKO Immunoturbidimetric assay on a Cobas Mira biochemical analyzer. The reference serum interval was 0.80-1.25 $\mathrm{mg} / \mathrm{L}$. Briefly, the assay was performed at room temperature with a six-point calibration covering the range of $0.23-7.25 \mathrm{mg} / \mathrm{L}$. The calibrator used was a purified CysC from human urine $(1.45 \mathrm{mg} / \mathrm{L})$. The sample volume was $80 \mu \mathrm{L}$. The time for analysis was 6 minutes; each subsequent sample reading was available after $8 \mathrm{~s}$. In our hands, the interassay CV $(n=20)$ was $<4 \%$ for both the low $(1.4 \mathrm{mg} / \mathrm{L})$ and high $(4.2 \mathrm{mg} / \mathrm{L})$ controls.

\section{Calculations}

The percentage of discordant changes in serum CysC and creatinine concentrations was calculated on a day-to-day basis after transplantation. A change in op- 
posite direction (increase/decrease) of $>10 \%$ between the two markers was considered as discordant. On hospital discharge or at the end of the 25 days period, $\mathrm{CrCl}$ was estimated from SCr using the formula of Cockcroft and Gault [14]. A cutoff of 80 $\mathrm{mL} / \mathrm{min}$ was selected for normal estimated $\mathrm{CrCl}$ [25].

\section{Statistical analysis}

Data are presented as mean \pm SD or as median and range when appropriate after checking for Gaussian distribution. Differences between two groups were evaluated by the Wilcoxon signed-rank test. Multiple comparisons were performed by the Friedman repeated-measure ANOVA on ranks followed by the Dunn test. Correlation between techniques was evaluated by linear regression and ANOVA. Results with $P<0.05$ were considered statistically significant.

\section{RESULTS}

Cys $C$ and creatinine concentration were measured in 50 healthy adults (39 \pm 9 years). Data were analyzed by linear regression and ANOVA $(P<0.05$ considered significant). The concentration of CysC significantly correlated $(r=0.625 ; P<$ 0.0001 ) with creatinine (Fig. 1). CysC serum concentration were not influenced by age $(r=0.195$; not significant). The calculated reference interval for creatinine was 58-109 mmol/L (males and females) and the CysC: 0.80-1.25 mg/L (Fig. 1).

Transplant patients were separated into two groups: with normal course (absent of complications; $n=38$ ); with DGF and with acute rejection episode defined as requiring hemodialysis during the first 2 week after surgery $(n=26)$. In patients without DGF a significant decline in serum concentration was more rapidly obtained for CysC that the creatinine (Fig. 2).

Starting on day 4 after transplantation the decrease in the serum concentration in patients without DGF was more pronounced for creatinine than the CysC.

In patients with DGF, the reduction in the serum concentration was not significant until day 14 for creatinine and day 17 for CysC.

At the end of the 25-day study period, a $50 \%$ reduction from the initial $\mathrm{SCr}$ concentration was observed in patients with DGF versus $35 \%$ for CysC. The frequency of discordant daily changes in CysC and creatinine values was significantly higher in patients with DGF (40\%) than dose without DGF $(21 \%, \mathrm{P}<0.01)$ (Fig. 3).

In cases with acute rejection episode as demonstrated by persistent increases in both $\mathrm{SCr}$ and $\mathrm{CysC}$ concentration, serum CysC gradually rose (115\%) during 7 days before diagnosis (FK506 induced nephrotoxicity regressed spontaneously).

At the end of the study (day 25), SCr was $150 \mu \mathrm{mol} / \mathrm{L}(79-602 \mu \mathrm{mol} / \mathrm{L})$ vs. 2.12 $\mathrm{mg} / \mathrm{L}(1.04-5.54 \mathrm{mg} / \mathrm{L})$ for CysC. Both markers significantly correlated $(r=0.812 ; P<$ 0.001 ). Estimated $\mathrm{CrCl}$ by the Cockcroft and Gault formula [14] in patients with stable renal function (no hemodialysis during the last week, $\mathrm{n}=19)$ was $49 \mathrm{~mL} / \mathrm{min}(15-66 \mathrm{~mL} /$ $\mathrm{min}$ ), and no patient was within the reference interval (> $80 \mathrm{~mL} / \mathrm{min})$. SCr was within the reference interval for three patients (80-109 $\mu \mathrm{mol} / \mathrm{L})$ compared with none for CysC. The 
relationship between estimated $\mathrm{CrCl}$ and the serum concentrations of creatinine and CysC in patients with stable renal function $(n=22)$ is represented in Fig. 4 and 5.

There was a significant correlation between estimated $\mathrm{CrCl}$ and the serum CysC $(r=0.714 ; P<0.001)$.
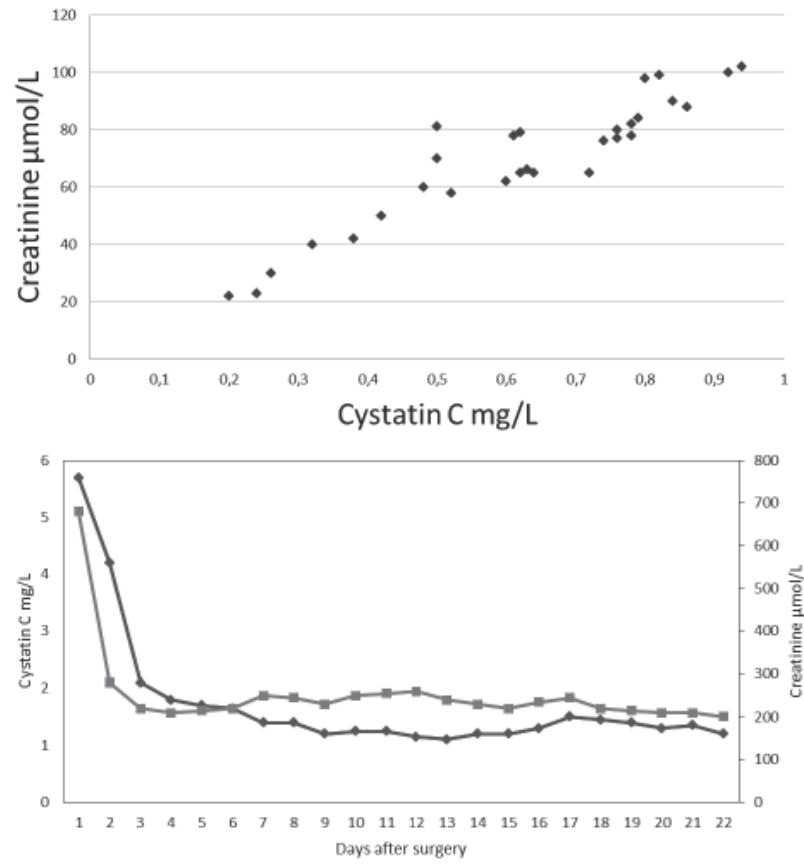

$\rightarrow$ cystatin $\rightarrow-$ creatinine

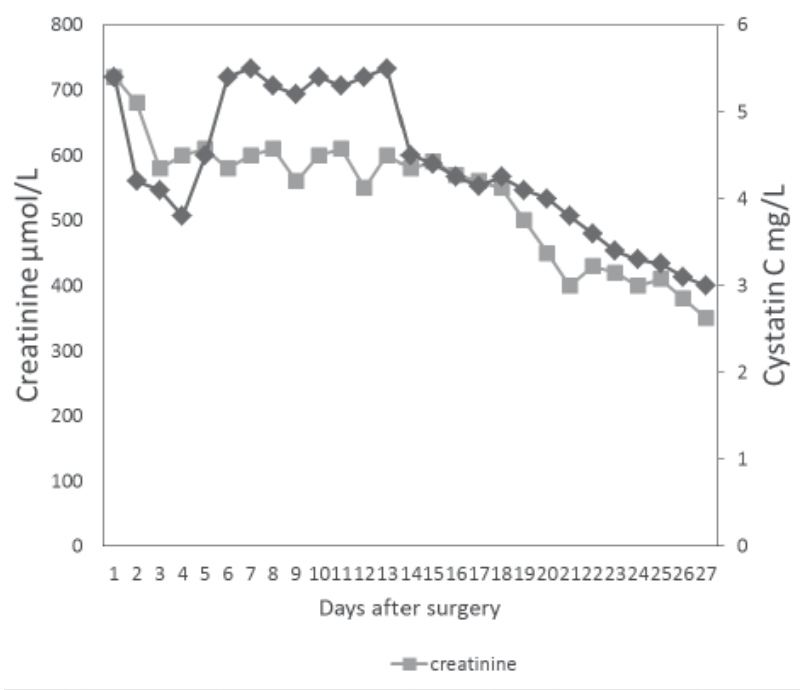

Fig. 1. Relationship between serum $\mathrm{CysC}$ and SCrin healthy controls $(r=0.625, p<0001)$

Fig. 2. Serum CysC and SCrin renal transplant patients without DGF

Fig. 3. Serum CysC and SCrin renal transplant patients with DGF 

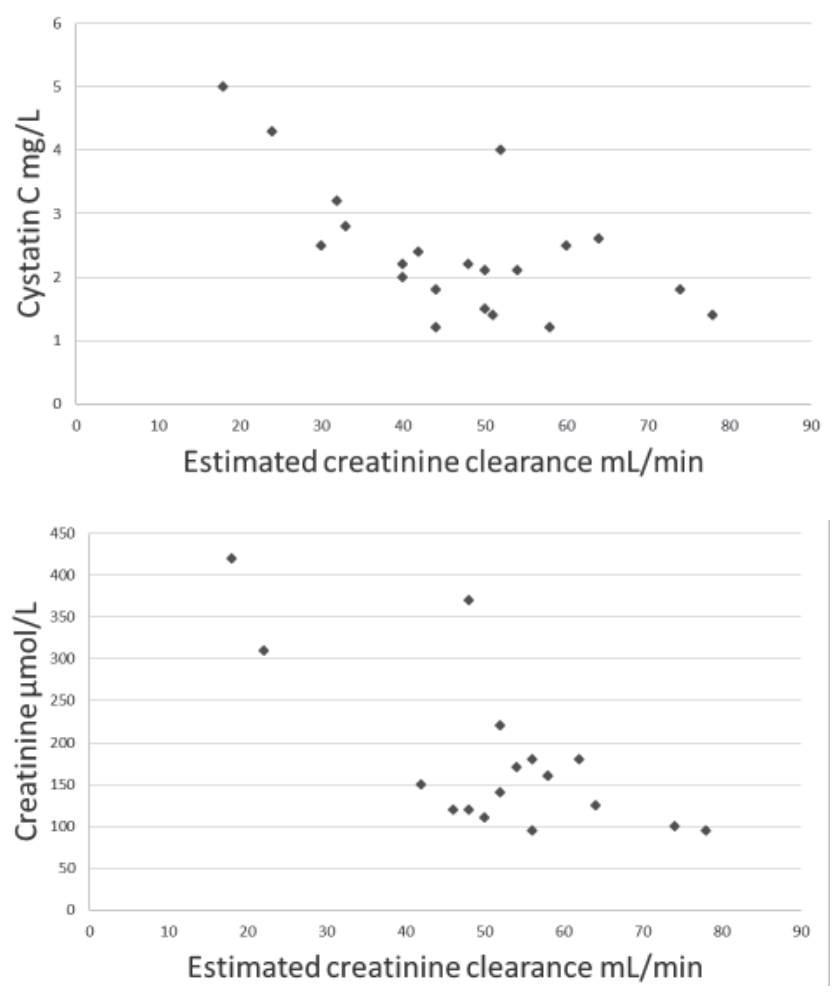

Fig. 4. Relationship between serum CysC and GFR

Fig. 5. Relationship between $\mathrm{SCr}$ and GFR

\section{DISCUSION}

Sensitive and reliable recognition of changes in GFR is of primary importance in transplant patients. A DGF is an identified and independent risk factor for graft survival [26]. Acute rejection is also an established risk factor for renal graft failure, defined as a return of patient to hemodialysis [18-20]. Recent studies have suggested that CysC might be a potential better marker of GFR than SCr [26-28] such as in renal transplant patients [31, 32].

The mean CysC serum concentration in our group of healthy adults was similar to that reported in a group of healthy subjects ( $n=50$; mean age 40 years), using an immunoturbidimetric assay $(0.65 \pm 0.05 \mathrm{mg} / \mathrm{L})$ [31]. Slightly higher values (mean CysC $0.80 \mathrm{mg} / \mathrm{L}$ ) were reported by other investigators [35] in a group of 52 adults with normal renal function (21-79 years old). These data are in agreement with an increase in serum CysC values with age, especially after the age of 50 years [35]. We found no difference in serum concentrations of cystatin $C$, influenced by gender, reported previously [32, 33]. Serum CysC correlated poorly with $\mathrm{SCr}$, as reported previously in subjects with GFR $>80 \mathrm{~mL} / \mathrm{min}$ [24] or GFR $>70 \mathrm{~mL} / \mathrm{min}^{-1} / 1.73 \mathrm{~m}^{-2}$ [23]. These data suggest that different physiological factors (such as age, dietary factors, or body composition) influence CysC and creatinine serum concentrations in healthy adults. 
In renal transplant patients, serum CysC concentrations paralleled those of creatinine regardless of graft function (absence or presence of DGF). Consequently, serum CysC and creatinine significantly correlated over the postoperative study period as observed previously in adult renal transplant patients [31] and subjects suffering from chronic renal disease [13]. Some differences, however, were apparent in their respective serum kinetics. During the first 4 days post transplantation, the Cys $\mathrm{C}$ serum concentration decreased more rapidly than that of creatinine. Transtubular leakage of the low-molecular weight ( $\mathrm{Mr} 100)$ creatinine [23] has been reported in acute renal failure, thus leading to high $\mathrm{SCr}$ values. Starting on day 4 post transplantation, the decrease in serum concentration became more prominent for creatinine than for CysC, which might be attributable to an underestimation of GFR by serum CysC, an overestimation of GFR by $\mathrm{SCr}$, or both. A stronger correlation between CysC than between creatinine and the measured GFR has been reported in adults suffering from renal diseases [18].

For patient follow-up, the ability to detect rapid changes in GFR is clinically more important than the accuracy itself. With diminished GFR, a significant increase in serum concentration of CysC and creatinine will depend on the rate of its accumulation in serum, which depends on its production rate and distribution volume, but also on its biological intraindividual variation. Repeated measures obtained in healthy subjects [31] suggested that intraindividual variation might be more important for CysC (13.3\%) than for creatinine $(4.9 \%)$. If true, CysC would be less sensitive for the detection of acute rejection episodes for a given individual than creatinine [31]. In all episodes of acute rejection and acute nephrotoxicity in our study, the serum $\mathrm{Cys} C$ concentration broadly paralleled that of creatinine. The rise in the serum Cys $\mathrm{C}$ concentration was more prominent than that of creatinine.

After renal transplantation, hemodialysis was required in almost $55 \%$ of our patients. We found a higher degree of discrepancy ( $45 \%$ of discordant results; $\mathrm{P}<$ 0.01 ) between $\mathrm{Cys} C$ and creatinine kinetics in patients requiring hemodialysis than in those with a normal course (19\%). In addition, CysC and creatinine weakly correlated in hemodialyzed patients $(r=0.429)$. The molecular weight of CysC is 13300 with an Einstein-Stokes radius of $30-40 \AA$, which is much higher than creatinine $(\mathrm{Mr}$ 100 and $3 \AA$ ) [15]. In a large study of 112 patients on stable maintenance hemodialysis, a $30 \%$ reduction in serum CysC was observed after dialysis mostly with AN69 high-flux membranes [23]. As expected, the elimination of CysC during dialysis increased with the ultrafiltration coefficient (UFC) of the membrane, an estimate of the permeability: $0 \%$ (vs. $40 \%$ for creatinine) for UFC $<15 \mathrm{~mL} \cdot \mathrm{h}^{-1} \cdot \mathrm{m}^{2} \cdot \mathrm{mmHg}$ and $\sim 60 \%$ (as for creatinine) for UFC $>15 \mathrm{~mL} \cdot \mathrm{h}^{-1} \cdot \mathrm{m}^{2} \cdot \mathrm{mmHg}$ [23]. Thus, removal of CysC by hemodialysis seems highly dependent on the type of membrane selected. This is an important issue in renal transplantation because it could limit the use of serum CysC as a marker of graft function in patients with DGF. On the other hand, if poorly filtered by dialysis membranes, serum CysC could be used by the nephrologist to monitor appropriate duration of hemodialysis in patients with DGF. Prolonged unnecessary 
hemodialysis could be avoided as soon as a significant decrease in serum CysC is obtained by dialysis.

In conclusion, the determination of CysC concentration is an alternative and more accurate marker of GFR than creatinine in adult transplantation. In some cases, a more prominent rise in serum Cys $\mathrm{C}$ values allows a more rapid diagnosis of acute rejection or treatment nephrotoxicity. Further prospective studies are needed to evaluate this last issue and the potential of serum $\mathrm{CysC}$ in the long term follow-up of graft function in renal transplantation.

\section{REFERENCES}

1. Grubb AO. Cystatin C - properties and use as diagnostic marker. Adv Clin Chem 2011; 35:63-99.

2. Vinge E, Lindergard B, Nilsson-Ehle P, Grubb A. Relationships among serum cystatin C, serum creatinine, lean tissue mass and glomerular filtration rate in healthy adults. Scand J Clin Lab Invest 1999; 59:587-592.

3. Finney $\mathrm{H}$, Newman DJ, Price CP. Adult reference ranges for serum cystatin $\mathrm{C}$, creatinine and predicted creatinine clearance. Ann Clin Biochem 2000; 37:49-59.

4. Swan SK. The search continues - an ideal marker of GFR [Editorial]. Clin Chem 1997; 43:913-914.

5. Newman DJ, Thakkar H, Edwards RG, et al. Serum cystatin C measured by automated immunoassay: a more sensitive marker of changes in GFR than serum creatinine. Kidney Int 1995; 47:312-318.

6. Bokenkamp A, Domanetzki M, Zinck R, Schumann G, Byrd D, Brodehl J. Cystatin C - a new marker of glomerular filtration rate in children independent of age and height. Pediatrics 1998; 101:875-881.

7. Helin I, Axenram M, Grubb A. Serum cystatin $\mathrm{C}$ as a determinant of glomerular filtration rate in children. Clin Nephrol 1998; 49:221-225.

8. Harmoinen AP, Kouri TT, Wirta OR, et al. Evaluation of plasma cystatin C as a marker for glomerular filtration rate in patients with type 2 diabetes. Clin Nephrol 1999; 52:363-370.

9. Plebani M, Dall'Amico R, Mussap M, et al. Is serum cystatin C a sensitive marker of glomerular filtration rate (GFR)? A preliminary study on renal transplant patients. Ren Fail 1998; 20:303-309.

10. Le Bricon $T$, Thervet $E$, Froissart $M$, et al. Plasma cystatin $C$ is superior to 24 -h creatinine clearance and plasma creatinine for estimation of glomerular filtration rate 3 months after kidney transplantation [Letter]. Clin Chem 2000; 46:1206-1207.

11. Herget-Rosenthal S, Trabold S, Huesing J, et al. Cystatin C - an accurate marker of glomerular filtration rate after renal transplantation?. Transpl Int 2000; 13:285-289.

12. Newman DJ, Thakkar H, Edwards RG, et al. Serum cystatin C: a replacement for creatinine as a biochemical marker of GFR. Kidney Int 1994; 46:S20-S21.

13. Le Bricon T, Tervet E. at al. Changes of Plasma Cystatin C after Renal transplantation and acute Rejection in Adults, Clinical Chemistry 1999; 45:2243-2249

14. Cockcroft DW, Gault MH. Prediction of creatinine clearance from serum creatinine. Nephron 1976; 16:31-34.

15. Perrone RD, Madias NE, Levey AS. Serum creatinine as an index of renal function: new insights into old concepts. Clin Chem 1992; 38:1933-1953.

16. Gowans E, Fraser CG. Biological variation of serum and urine creatinine and creatinine clearance: ramifications for interpretation of results and patient care. Ann Clin Biochem 1988; 25:259-263.

17. Young DS. Effects of drugs on clinical laboratory tests, 2nd ed. Washington, DC: AACC Press, 1990:1465.

18. Nilsson-Ehle P, Grubb A. New markers for determination of GFR: iohexol clearance and cystatin C serum concentration. Kidney Int 1994; 46:17-19. 
19. Grubb A. Diagnostic value of analysis of cystatin $\mathrm{C}$ and protein $\mathrm{HC}$ in biological fluids. Clin Nephrol 1992; 38:20-27.

20. Abrahamson M, Olafsson I, Palsdottir A, Ulvsback M, Lundwall A, Jensson O, Grubb A. Structure, expression of the human cystatin C gene. Biochem J 1990; 268:287-294.

21. Norlund L, Fex G, Lanke J. et al. Reference intervals for the glomerular filtration rate and cellproliferation markers: serum cystatin $\mathrm{C}$ and serum $\beta_{2}$-microglobulin/cystatin C-ratio. Scand J Clin Lab Investig 1997; 57:463-470.

22. Tenstad O, Roald AB, Grubb A, Aukland K. Renal handling of radiolabelled human cystatin $C$ in the rat. Scand J Clin Lab Investig 1996; 56:409-414.

23. Kabanda A, Jadoul M, Pochet JM, et al. Determinants of the serum concentrations of low molecular weight proteins in patients on maintenance hemodialysis. Kidney Int 1994; 1689-1696.

24. Plebani M, Dall'Amico R, Mussap M, et al. Is serum cystatin C a sensitive marker of glomerular filtration rate (GFR)? A preliminary study on renal transplant patients. Renal Fail 1998; 20:303-309.

25. Shemesh O, Golbetz H, Kriss JP, Myers BD. Limitations of creatinine as a filtration marker in glomerulopathic patients. Kidney Int 1985; 28:830-838.

26. Richards E, Schleibner S, Talbot D. The European Tacrolimus Multicentre Renal Study Group. An exploratory analysis of prognostic factors for patient outcome during the first year following renal transplantation. Transplant Proc 1998; 1386-1388.

27. Randers E, Erlandsen EJ, Pedersen OL, Hasling C, Danielsen H. Serum cystatin C as an endogenous parameter of the renal function in patients with normal to moderately impaired kidney function. Clin Nephrol 2000; 54:203-209.

28. Keevil BG, Kilpatrick ES, Nichols SP, Maylor PW. Biological variation of cystatin C: implications for the assessment of glomerular filtration rate. Clin Chem 1998; 44:1535-1539

29. Newman D, Thakkar H, Edwards R. et al. Serum cystatin C measured by automated immunoassay: a more sensitive marker of changes in GFR than serum creatinine. Kidney Int 1995; 47:312-318.

30. Kyse-Andersen J, Schmidt C, Nordin G. et al. Serum cystatin C, determined by a rapid, automated particle-enhanced turbidimetric method, is a better marker than serum creatinine for glomerular filtration rate. Clin Chem 1994; 40:1921-1926.

31. Keevil BG, Kilpatrick ES, Nichols SP, Maylor PW. Biological variation of cystatin C: implications for the assessment of glomerular filtration rate. Clin Chem 1998; 44:1535-1539.

32. Jung K, Jung M. Cystatin C. A promising marker to replace creatinine. Nephron 1995; 70:371-372.

33. Pergande $M$, Jung $K$. Sandwich enzyme immunoassay of cystatin $C$ in serum with commercially available antibodies. Clin Chem 1993; 39:1885-1890.

34. Myers BD, Chui F, Hilberman M, Michaels AS. Transtubular leakage of glomerular filtrate in human acute renal failure. Am J Physiol 1979; 237:F319-F325.

35. Mussap M, Ruzzante N, Varagnolo M, Plebani M. Quantitative automated particle-enhanced immunonephelometric assay for the routinely measurement of human cystatin C. Clin Chem Lab Med 1998; 36:859-865.

\section{Corresponding author:}

Prof. Dr. Todor Gruev

Institute for Clinical Biochemistry

University Clinical Center

Vodnjanska str.17

1000 Skopje, Macedonia

tel. ++3892119080

++ 3892112539

e-mail: todorgruev@hotmail.com 